\title{
Socio-economic pathways to diet: modelling the association between socio-economic position and food purchasing behaviour
}

\author{
Gavin Turrell ${ }^{1, *}$ and Anne M Kavanagh ${ }^{2}$ \\ 'School of Public Health, Queensland University of Technology, Victoria Park Road, Kelvin Grove, Brisbane, \\ Queensland 4059, Australia: ${ }^{2}$ Key Centre for Women's Health in Society, School of Population Health, University \\ of Melbourne, Victoria 3010, Australia
}

Submitted 2 February 2005: Accepted 18 July 2005

\begin{abstract}
Objectives: To examine the association between education level and food purchasing behaviour and the contribution of dietary knowledge to this relationship; and the association between household income and purchasing behaviour and the contribution made by subjective perceptions about the cost of healthy food.

Design and setting: The study was conducted in Brisbane City (Australia) in 2000. The sample was selected using a stratified two-stage cluster design. Data were collected by face-to-face interview from residents of private dwellings $(n=1003)$, and the response rate was $66.4 \%$. Dietary knowledge was measured using a 20 -item index that assessed general knowledge about food, nutrition, health and their interrelationships. Food-cost concern was measured using a three-item scale derived from principal components analysis $(\alpha=0.647)$. Food purchasing was measured using a 16-item index that reflected a household's purchase of grocery items that were consistent (or otherwise) with dietary guideline recommendations. Associations among the variables were analysed using linear regression with adjustment for age and sex. Results: Significant associations were found between education, household income and food purchasing behaviour. Food shoppers with low levels of education, and those residing in low-income households, were least likely to purchase foods that were comparatively high in fibre and low in fat, salt and sugar. Socio-economic differences in dietary knowledge represented part of the pathway through which educational attainment exerts an influence on diet; and food purchasing differences by household income were related to diet in part via food-cost concern.

Conclusions: Our findings suggest that socio-economic differences in food purchasing behaviour may contribute to the relationship between socio-economic position and food and nutrient intakes, and, by extension, to socio-economic health inequalities for diet-related disease. Further, socio-economic differences in dietary knowledge and concerns about the cost of healthy food play an important role in these relationships and hence should form the focus of future health promotion efforts directed at reducing health inequalities and encouraging the general population to improve their diets.
\end{abstract}

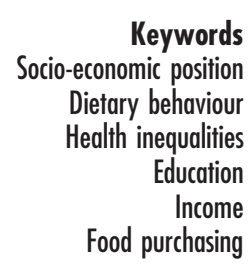

A growing literature documents an association between socio-economic position (SEP) and diet, and most of this work shows that disadvantaged groups have dietary profiles that are least consistent with recommended daily intakes or healthy eating messages promulgated in health promotion programmes or dietary guidelines ${ }^{1-5}$. Increasingly, it is being suggested that the diets of socioeconomically disadvantaged groups contribute to their poorer health status ${ }^{6,7}$, as indicated by their higher mortality and morbidity rates for conditions such as coronary heart disease ${ }^{8-10}$, type 2 diabetes ${ }^{11,12}$ and some cancers $^{13,14}$.

To date, most studies examining the relationship between SEP and diet have focused on food and nutrient intake measured on the basis of mean daily intakes, nutrient density levels or percentage contribution of food to nutrition and energy ${ }^{15}$. Far fewer studies have investigated whether socio-economic groups differ in the dietary behaviours that necessarily precede the intake of food and nutrients, such as food purchasing choices. Studying food purchasing behaviour is clearly important, as earlier research has shown that the type of food that people buy influences dietary quality and that nutrient intake differences between socio-economic groups are partly the result of concomitant differences in food choice $^{16,17}$. Moreover, people usually shop for food and not nutrients ${ }^{18}$, thus many health promotion and education campaigns aimed at disseminating dietary 
guideline messages have typically encouraged the general public to make 'healthy' food choices when shopping; that is, food which is comparatively high in fibre and low in fat, salt and sugar ${ }^{19,20}$.

In previous studies we have shown that socio-economic groups differ significantly in their food purchasing behaviours, with disadvantaged groups being least likely to buy food that is consistent with minimal risk for the development of diet-related disease ${ }^{4,15,21}$. In the present paper we build on and extend this earlier work by examining some of the reasons why socio-economic groups differ in their food purchasing behaviours. A number of recent studies have suggested that the three most commonly used indicators of SEP in dietary research - education, occupation and income - tap different dimensions of the socio-economic construct and therefore may reflect distinct aetiological pathways between socioeconomic circumstances and diet ${ }^{22,23}$. Education level, for example, reflects the attainment of human capital via formal education, accreditation and lived-experience, and may influence the acquisition of knowledge about healthy dietary practices ${ }^{24}$ or facilitate or constrain one's ability to understand information communicated in nutrition education messages or on food labels ${ }^{25,26}$. Occupation may affect diet through work-based cultures, food availability in the workplace environment or social networks and peer groups $^{22}$. Income is likely to reflect the availability of economic and material resources, and hence influence dietary quality by making healthy food more or less affordable and accessible $\mathrm{e}^{27-29}$. To date, very little dietary research has delved deeper into the relationship between SEP and diet on the basis of intermediate (intervening) variables that seemingly constitute some of the pathways via which SEP influences the type of foods we buy. In this paper, we focus on two socio-economic indicators education and income - and investigate the contribution of dietary knowledge to educational inequalities in food purchasing behaviour; and the contribution of food-cost concern to household income differences in purchasing behaviour. Specifically, with respect to education we hypothesise that:

1. Food shoppers with lower levels of education will exhibit lower levels of knowledge about food and nutrition and their links with health;

2. Food shoppers with lower levels of education will exhibit a food purchasing pattern that is least consistent with dietary guideline recommendations; and

3. Educational differences in knowledge will make a significant contribution to educational variation in food purchasing.

In terms of household income, we hypothesise that:

1. Food shoppers from low-income households will be more likely than their higher-income counterparts to report that the cost of food represents a barrier to the purchase of healthy food;

2. Food shoppers from low-income households will exhibit a food purchasing pattern that is least consistent with dietary guideline recommendations; and

3. Differences in food-cost concern between low- and high-income households will partly account for differences in their choice of healthy food when shopping.

\section{Methods}

In this paper we examine the relationship between SEP and food purchasing behaviour using data from the Brisbane Food Study (BFS), a population-based project that used a multilevel methodology to estimate the relative contributions of neighbourhood- and individual-level factors to socio-economic variability in food purchasing behaviour. Details of the scope and coverage of the BFS, and its research design, sampling and data collection methods have been reported elsewhere ${ }^{30}$.

\section{Sample design}

The BFS was conducted in the Brisbane City Statistical Sub-Division (SSD). The sample comprised 1003 households and 50 Census Collectors Districts (CCDs), and was selected using a stratified two-stage cluster design. A CCD is the smallest administrative unit used by the Australian Bureau of Statistics to collect census data. As of 1996, the Brisbane SSD consisted of 1517 contiguous CCDs, each containing an average of 200 occupied private dwellings. Stratification consisted of ranking the CCD on the basis of each area's Index of Relative Socio-economic Disadvantage (IRSD) score. A CCD's IRSD score reflects the overall level of socio-economic disadvantage of each area measured on the basis of attributes such as low income, low educational attainment, and high levels of public sector housing, unemployment and jobs in relatively unskilled occupations ${ }^{31}$. The distribution of IRSD scores was subsequently divided into 10 strata (deciles) and five CCD were selected from each of the strata using systematic without-replacement probability proportional to size sampling. Stage 2 involved selecting 1003 private dwellings from the 50 CCDs (20 dwellings on average per CCD), and this was undertaken using simple random sampling. Given the focus of the study, we interviewed the person within each dwelling who was primarily responsible for most of the food shopping. A final response rate of $66.4 \%$ was achieved ${ }^{30}$.

\section{Data collection and survey instrument}

The individual-level data collection took place between September and December 2000, and was conducted on the basis of face-to-face interviews. Interviews lasted an 
average of $1 \mathrm{~h}$, and respondents were offered a small financial gratuity (AUS\$10.00) to offset any inconvenience that might have resulted from involvement in the study. The interview schedule was administered by trained interviewers and sought information on food purchasing choices, factors influencing choice, shopping patterns and practices, subjective perceptions of food availability and food prices, food expenditure, dietary knowledge, and the sociodemographic characteristics of the respondent and other household head (if a couple household).

\section{Measures}

\section{Education}

Respondents were asked to provide information about whether they had attained further education since leaving school and, if so, the highest qualification completed. Respondent's education was subsequently coded as (1) bachelor degree or higher (the latter included postgraduate diploma, masters degree or doctorate); (2) diploma (associate or undergraduate); (3) vocational (trade or business certificate, or apprenticeship); and (4) no post-school qualifications. In addition, a small number of respondents either refused to supply details about their educational qualifications or provided insufficient information for their education level to be reliably determined ( $n=25,2.5 \%$ ). Rather than exclude this group from the study, we created a fifth education category that allowed these respondents to be kept in the analysis (thereby retaining their data on other variables), although we do not report any findings for this group.

\section{Housebold income}

Respondents were asked to estimate the total income (including pensions, allowances and investments) received by all household members, and to indicate this using a single measure comprising 14 narrow-ranged income categories. This measure was subsequently recoded into four categories: (1) less than AUS\$20 799; (2) AUS\$20 800-36399; (3) AUS\$36400-51999; and (4) AUS\$52000 or more. Households in categories 1 and 2 received incomes at or below the Australian average as at 2000 , and those in categories 3 and 4 , above the average ${ }^{32}$. For various reasons (e.g. refused, didn't know), a small number of respondents could not be assigned to an income category ( $n=28,2.8 \%$ ), and these were handled in an identical manner to that described for the education measure.

\section{Dietary knowledge}

Respondents' dietary knowledge was measured using a pre-coded structured question comprising 20 statements administered using a true/false format which included a 'don't know' response option. The items dealt with a diverse range of issues pertaining to food, nutrition, health and their interrelationships, and were chosen by an 'expert panel' of dietitians and nutritionists to reflect a person's general knowledge. The panel was provided with information about the aims of the study (i.e. to investigate factors influencing food purchasing decisions) and the intended purpose of the dietary knowledge index, along with a list of items (newly derived and previously used) that tapped different aspects of knowledge about food, nutrition and health. The panel was asked to comment on the appropriateness and suitability of the items vis-à-vis their proposed usage, and the set of final items was achieved by discussion (and if necessary, modification of items) until consensus was reached. When deriving the index, it was not the intention to select a narrow range of statements that measured a person's knowledge about a specific (single) aspect of diet. Whilst it is acknowledged that both specific and more general forms of knowledge are likely to influence our food-related decisions, the latter were considered to have greater salience in terms of a person's everyday food purchasing behaviours. The items were presented in the survey in a random 'balanced' format, meaning that in order to indicate a correct answer for all items the respondent was required to report 'true' for 10 items and 'false' for 10 items: this approach was used to minimise the possibility of response acquiescence. Table 1 presents the knowledge items and indicates in ascending order the proportion of respondents who provided an incorrect answer.

A dietary knowledge index was constructed that measured the extent to which respondents were correct or incorrect across all 20 statements. An initial step involved coding each correct response to 1 and incorrect and 'don't know' responses to 0 . This is known as a 'strict' scoring procedure in that both incorrect and 'don't know' answers are seen to be equally indicative of a lack of knowledge on any particular item; thus respondents are separated into two groups for each statement - they either provided the correct answer or they did not. This method of scoring true-false knowledge items has been used in previous dietary research ${ }^{33}$. Once assigned a score of 0 or 1 for each of the statements, respondents' scores were summed to produce an index that ranged from 0 to 20 .

\section{Food-cost concern}

As part of the interview schedule, respondents were asked 'To what extent do you agree or disagree with these statements?' What followed were 16 statements that pertained to health and financial factors that may have influenced the household's food purchasing decisions. Response options ranged from $1=$ 'strongly agree' to $5=$ 'strongly disagree'. The 16 items were submitted to principal components analysis using the PROC FACTOR procedure in $\mathrm{SAS}^{34}$. Rotation was performed using the Varimax option. Four components were identified with eigenvalues greater than unity and a cumulative variance 
Table 1 Food and nutrition knowledge items: percentage of respondents $(n=1000)$ reporting the incorrect answer (ranked in ascending order)

\begin{tabular}{|c|c|}
\hline & $\%$ incorrect \\
\hline $\begin{array}{l}\text { It is better for health to choose lean meat } \\
\text { (with little visible fat) }\end{array}$ & 3.4 \\
\hline $\begin{array}{l}\text { It is better for health to limit those foods which } \\
\text { contain high levels of sugar such as soft } \\
\text { drinks, cordial and biscuits }\end{array}$ & 5.1 \\
\hline $\begin{array}{l}\text { Adequate calcium intake may reduce the } \\
\text { risk of osteoporosis }\end{array}$ & 6.0 \\
\hline $\begin{array}{l}\text { It is recommended that adults have some milk, } \\
\text { cheese or yoghurt every day }\end{array}$ & 7.4 \\
\hline Fruit is a poor source of vitamin C & 8.4 \\
\hline Whole-grain breads are good sources of fibre & 8.8 \\
\hline $\begin{array}{l}\text { It is recommended that we eat fat and oil in } \\
\text { limited amount }\end{array}$ & 9.0 \\
\hline $\begin{array}{l}\text { Bread, cereal, fruit and vegetables should } \\
\text { make up the smallest part of our diet }\end{array}$ & 11.1 \\
\hline $\begin{array}{l}\text { Dietary fibre from wholemeal foods combined } \\
\text { with an adequate intake of drinking } \\
\text { water prevents constipation }\end{array}$ & 15.1 \\
\hline $\begin{array}{l}\text { Low sugar intake may decrease the } \\
\text { risk of dental cavities }\end{array}$ & 15.3 \\
\hline $\begin{array}{l}\text { Saturated fats are found in large quantities in } \\
\text { butter, lard and dripping }\end{array}$ & 17.4 \\
\hline $\begin{array}{l}\text { A high intake of saturated fat can protect } \\
\text { against heart disease }\end{array}$ & 19.1 \\
\hline $\begin{array}{l}\text { Choosing wholemeal bread provides no } \\
\text { health benefits }\end{array}$ & 21.2 \\
\hline $\begin{array}{l}\text { Choosing salt-reduced food provides no } \\
\text { health benefits }\end{array}$ & 25.2 \\
\hline $\begin{array}{l}\text { Adults should choose full-cream milk instead } \\
\text { of Skim or Trim milk }\end{array}$ & 25.7 \\
\hline $\begin{array}{l}\text { Meat, fish, chicken and eggs should make up } \\
\text { the largest part of our diet }\end{array}$ & 29.0 \\
\hline $\begin{array}{l}\text { A high intake of plant food combined with a low salt } \\
\text { intake may protect against high blood pressure }\end{array}$ & 32.1 \\
\hline $\begin{array}{l}\text { Milk and milk products such as cheese and } \\
\text { yoghurt are the best sources of iron }\end{array}$ & 32.6 \\
\hline Meat, poultry and fish are the best sources of calcium & 32.8 \\
\hline $\begin{array}{l}\text { Dark green and orange vegetables like spinach, } \\
\text { broccoli, carrots and pumpkin are low in vitamin A }\end{array}$ & 48.2 \\
\hline
\end{tabular}

that totalled $60.5 \%$. Of these, we retained a three-item component that was conceptually meaningful for the study's purpose (eigenvalue $=1.72$ ). The component explained $8.2 \%$ of the total variance, and comprised the following statements and their factor loadings: Sometimes my family cannot afford to buy enough food for our needs (0.758); When buying food for my family my choice is influenced by the price of the food (0.752); and Sometimes my family cannot afford to buy healthy and nutritious food (0.711). Standardised scoring coefficients were calculated for the items forming the component and these were used to derive a factor scale (Cronbach's $\alpha=0.647$ ) which was subsequently interpreted as a measure of food-cost concern. The standardised scale was re-scored to range from 0 to 100, with higher scores indicating greater levels of concern about food costs.

\section{Food purchasing}

Food purchasing behaviour was examined on the basis of 16 grocery foods (including meat and chicken), with each question having two or more response categories. For example, respondents were asked: 'When you go shopping, what type of bread do you usually buy?' The response options included: I do not buy bread, white, wholemeal, multigrain, white high in fibre, rye, soy \& linseed, plus others. Multiple responses were permitted for each question. The other 15 questions were structured in an identical manner and pertained to rice, pasta, baked beans, fruit juice, tinned fruit, milk, cheese, yoghurt, beef mince, chicken, tinned fish, vegetable oil, margarine, butter and solid cooking fat. In Australia, health promotion and education campaigns directed at disseminating dietary guideline messages recommend that people purchase and consume a variety of nutritious foods that are comparatively high in fibre and low in fat, salt and sugar ${ }^{19,35}$. In keeping with these campaigns, we classified respondents' food purchasing choices into a 'recommended' and 'regular' category (Table 2). Purchasing patterns for each grocery food type were then scored as follows. Respondents were categorised as never purchasing the food (scored 0), as purchasing the regular option exclusively (scored 1), as purchasing a variety of food that included both the recommended and regular options (scored 2), or as purchasing the recommended option exclusively (scored 3). The food types were then summed to form a purchasing index, and using an approach described elsewhere the index scores were adjusted to account for the fact that some people did not purchase particular foods ${ }^{4,15}$. This index was then scaled to range from 0 to 100, with high scores being indicative of greater compliance with dietary guideline recommendations.

\section{Analysis}

Of the 1003 respondents interviewed for the BFS, three provided insufficient information for their knowledge scores to be reliably assessed; each of these respondents was excluded, resulting in a final useable sample of 1000 . Table 3 presents descriptive statistics for the measures used in this analysis.

The complex two-stage cluster design of the BFS produced a correlation structure among the observations, which if ignored in the analysis would lead to incorrect estimates of standard errors and an increased probability of incurring a type 1 error $^{36,37}$. Within-area clustering was accounted for by analysing the data as a two-level random intercept model using MLwinN version $2.1 \mathrm{c}^{38}$. Substantive interest for this paper is exclusively on the individual-level fixed effects: output from the random-effects (i.e. arealevel) variance is not reported.

The associations between education, dietary knowledge and food purchasing behaviour were examined using multilevel linear regression, and we adopted a four-stage modelling strategy with adjustment for age and sex at each stage. Model 1 examines the association between education and dietary knowledge, and Model 2 examines the relationship between education and food purchasing 
Table 2 Classification of grocery food types into 'recommended' and 'regular' categories*

\begin{tabular}{|c|c|c|}
\hline Food type & Recommended $\dagger$ & Regular \\
\hline Bread & $\begin{array}{l}\text { Wholemeal, multigrain, white high in fibre, } \\
\text { rye, soy \& linseed }\end{array}$ & White \\
\hline Rice & Wholemeal or brown & White \\
\hline Pasta & Wholemeal or brown & White \\
\hline Baked beans & Salt-reduced or unsalted & Regular salt \\
\hline Fruit juice & No added sugar (unsweetened) & Added sugar, fruit drink (5-35\% fruit juice) \\
\hline Tinned fruit & In natural juice & In syrup \\
\hline Milk & $\begin{array}{l}\text { Reduced-fat (Trim), low-fat (Skim), high-calcium (Physical, } \\
\text { Shape), high-calcium skimmed (Physical), high-iron (Life), } \\
\text { high-protein (Lite White), reduced-lactose (Lactaid), no } \\
\text { cholesterol (Dairy Wise), soy or soy \& linseed (Skim) }\end{array}$ & $\begin{array}{l}\text { Extra creamy, full cream, soy or soy } \\
\quad \& \text { linseed (full cream) }\end{array}$ \\
\hline Cheese & Reduced-fat (25\% less fat), low-fat (<10\% fat) & Full-fat \\
\hline Yoghurt & Low-fat (plain and fruit) & Full-fat (plain and fruit) \\
\hline Beef mince & Lean (Trim/Premium) & Regular (Choice/Fine Grade) \\
\hline Chicken & $\begin{array}{l}\text { Breast fillet without skin, thigh fillet } \\
\text { without skin, drumstick without skin }\end{array}$ & $\begin{array}{l}\text { Breast fillet with skin, thigh fillet } \\
\text { with skin, drumstick with skin, wings, } \\
\text { whole chicken with skin }\end{array}$ \\
\hline Tinned fish & In spring water & In oil or brine \\
\hline Vegetable oil & Canola, sunflower, safflower, olive, corn, soy, sesame & Peanut, sesame, blended edible, macadamia \\
\hline Margarine & Salt-reduced, fat-reduced & Regular salt, full-fat \\
\hline Butter & Salt-reduced, unsalted & Regular salt \\
\hline Solid cooking fat & Margarine, solidified oil & $\begin{array}{l}\text { Solid animal fat (lard, beef dripping), } \\
\text { vegetable shortening }\end{array}$ \\
\hline
\end{tabular}

* Food types were chosen based on those included in the five core food groups of the Australian Guide to Healthy Eating ${ }^{35}$.

$\dagger$ Food options endorsed in dietary guideline publications and considered preferable choices to minimise risk for the development of diet-related diseases.

behaviour. In Model 3, we present the association between education and food purchasing behaviour adjusted for dietary knowledge, and Model 4 further adjusts this association for household income. At each stage, tests for improvements in model fit were assessed using the deviance statistic. Results of all the regression analyses are expressed as parameter estimates that reflect the absolute difference in food purchasing scores relative

Table 3 Descriptive statistics for sociodemographic indicators, knowledge index, food-cost concern scale and food purchasing index $(n=1000)$

\begin{tabular}{lc}
\hline Age of main food purchaser (years), & $45.6(16.8), 43.0$ \\
mean (SD), median & \\
Sex of main food purchaser, $n(\%)$ & $217(21.7)$ \\
$\quad$ Male & $783(78.3)$ \\
Female & \\
Education level of main food purchaser, $n(\%)$ & $269(26.9)$ \\
$\quad$ Bachelor degree or higher & $105(10.5)$ \\
Diploma & $189(18.9)$ \\
Vocational & $414(41.4)$ \\
No post-school qualification & $23(2.3)$ \\
Other (not classifiable) & \\
Household income (AUS\$), $n(\%)$ & $410(41.0)$ \\
52000 or more & $173(17.3)$ \\
$36400-51999$ & $206(20.6)$ \\
$20800-36399$ & $185(18.5)$ \\
$\leq 20799$ & $26(2.6)$ \\
Other (not classifiable) & $16.2(3.3), 17.0$ \\
Dietary knowledge index, mean (SD), median* & \\
Food-cost concern scale, mean (SD), median† & $44.2(16.4), 43.9$ \\
Grocery food purchasing index, mean (SD), & $51.3(17.6), 50.0$ \\
median† & \\
\hline
\end{tabular}

SD - standard deviation.

* The dietary knowledge index ranged from 0 to 20 .

†The food-cost concern scale and food purchasing index ranged from 0 to 100 . to a reference group, and their 95\% confidence intervals (CIs). The associations between household income, foodcost concerns and food purchasing behaviour were examined using an identical modelling strategy to that just outlined for education, dietary knowledge and purchasing behaviour.

\section{Results}

Table 4 (Model 1) shows a statistically significant association between education and dietary knowledge: respondents holding a bachelor degree or higher scored highest on the knowledge index and those with no postschool education scored lowest. Models 2 and 3 respectively in Table 4 show the effects of education level on food purchasing prior to and after adjustment for dietary knowledge. Prior to adjustment, respondents with no post-school education were least likely to have a purchasing profile consistent with healthy food purchasing messages (Model 2). When dietary knowledge was added to Model 2 it resulted in a substantial attenuation of the relationship between education and food purchasing, with the effects being most evident for those education groups who scored lowest on the knowledge index (Model 3). Dietary knowledge was independently related to food purchasing - a one unit increase on the knowledge index was associated with an average increase of 1.28 (95\% CI $0.94,1.61)$ units on the purchasing measure. The inclusion of knowledge significantly improved the overall fit of the model relative to the unadjusted model $\left(\chi^{2}=54.2, P \leq 0.0001\right)$. The relationship between education and food purchasing behaviour 
Table 4 Modelling the association between education and dietary knowledge (Model 1), and education and grocery food purchasing (Model 2) adjusted for dietary knowledge (Model 3) plus household income (Model 4$)^{\star}(n=1000)$

\begin{tabular}{|c|c|c|c|c|c|c|c|c|}
\hline & \multirow{2}{*}{\multicolumn{2}{|c|}{$\frac{\text { Dietary knowledge } \dagger}{\text { Model } 1}$}} & \multicolumn{6}{|c|}{ Grocery food purchasingł } \\
\hline & & & \multicolumn{2}{|r|}{ Model 2} & \multicolumn{2}{|r|}{ Model 3} & \multicolumn{2}{|c|}{ Model 4} \\
\hline & $\beta$ & $95 \% \mathrm{Cl}$ & $\beta$ & $95 \% \mathrm{Cl}$ & $\beta$ & $95 \% \mathrm{Cl}$ & $\beta$ & $95 \% \mathrm{Cl}$ \\
\hline \multicolumn{9}{|l|}{ Education level } \\
\hline $\begin{array}{l}\text { Bachelor's degree } \\
\text { or higher }\end{array}$ & - & 1.00 & - & 1.00 & - & 1.00 & - & 1.00 \\
\hline Diploma & -0.57 & $-1.27,0.13$ & -4.89 & $-8.79,-1.00$ & -4.10 & $-7.89,-0.30$ & -2.73 & $-6.52,1.06$ \\
\hline Vocational & -1.40 & $-1.98,-0.82$ & -3.43 & $-6.65,-0.21$ & -1.59 & $-4.75,1.58$ & 0.07 & $-3.16,3.30$ \\
\hline $\begin{array}{l}\text { No post-school } \\
\text { education }\end{array}$ & -1.75 & $-2.24,-1.27$ & -5.20 & $-7.88,-2.51$ & -2.90 & $-5.58,-0.22$ & -1.05 & $-3.78,1.69$ \\
\hline Dietary knowledge & - & - & - & - & 1.28 & $0.94,1.61$ & 1.25 & $0.91,1.58$ \\
\hline $\begin{array}{l}\text { Deviance } \\
P \text {-value for } \\
\quad \text { deviance test }\end{array}$ & & & & 8529.50 & & $\begin{array}{l}8475.27 \\
\leq 0.0001 \S\end{array}$ & & $\begin{array}{l}460.37 \\
.0059\end{array}$ \\
\hline
\end{tabular}

$\mathrm{Cl}$ - confidence interval.

*Analyses adjusted for age and sex of person in household mostly responsible for food purchasing.

$\dagger$ Index measuring dietary knowledge ranged from 0 to 20

$\ddagger$ Scale measuring grocery food purchasing ranged from 0 to 100 .

$\S P$-value for the difference between the deviance for Model 2 and Model 3.

I $P$-value for the difference between the deviance for Model 3 and Model 4.

was attenuated to non-significance after adjustment for income (Model 4), although the association between dietary knowledge and purchasing behaviour was little affected. The impact of income on the association between education and food purchasing was also apparent based on the deviance test, which showed a significant improvement in model fit with the inclusion of income $\left(\chi^{2}=14.9, P=0.005\right)$.

Table 5 (Model 1) shows a strong association between household income and food-cost concern, with respondents from low-income households being significantly more likely to report that food costs represented a barrier to the purchase of (healthy) food. Models 2 and 3 respectively in Table 5 show the effects of household income on food purchasing prior to and after adjustment for food-cost concern. Prior to adjustment, a graded association was observed between household income and the purchase of grocery foods, with those in low-income households being least likely to exhibit a purchasing pattern consistent with nutrition messages. When foodcost concern was added to Model 2 it resulted in a noticeable attenuation of the relationship between household income and food purchasing behaviour (Model 3), although income was still strongly related with food purchase. Food-cost concern was independently related with food purchase: a one unit increase on the concern index was associated with an average decrease of -0.11 (95\% CI - 0.18, - 0.04) units on the purchasing measure. The inclusion of the food-cost scale significantly improved the overall fit of the model relative to Model $2\left(\chi^{2}=10.08\right.$,

Table 5 Modelling the association between household income and food-cost concern (Model 1), and income and grocery food purchasing (Model 2) adjusted for food-cost concern (Model 3) plus education (Model 4)* $(n=1000)$

\begin{tabular}{|c|c|c|c|c|c|c|c|c|}
\hline & \multirow{2}{*}{\multicolumn{2}{|c|}{$\frac{\text { Food-cost concern } \dagger}{\text { Model } 1}$}} & \multicolumn{6}{|c|}{ Grocery food purchasing } \\
\hline & & & \multicolumn{2}{|r|}{ Model 2} & \multicolumn{2}{|c|}{ Model 3} & \multicolumn{2}{|c|}{ Model 4} \\
\hline & $\beta$ & $95 \% \mathrm{Cl}$ & $\beta$ & $95 \% \mathrm{Cl}$ & $\beta$ & $95 \% \mathrm{Cl}$ & $\beta$ & $95 \% \mathrm{Cl}$ \\
\hline \multicolumn{9}{|c|}{ Household income (AUS\$) } \\
\hline 52000 or more & - & 1.00 & - & 1.00 & - & 1.00 & - & 1.00 \\
\hline $36400-51999$ & 4.70 & $-8.29,-2.24$ & -5.27 & $-8.29,-2.24$ & -4.69 & $-7.72,-1.66$ & -4.41 & $-7.47,-1.35$ \\
\hline $20800-36399$ & 10.09 & $-9.75,-4.01$ & -6.88 & $-9.75,-4.01$ & -5.69 & $-8.64,-2.75$ & -5.30 & $-8.32,-2.28$ \\
\hline$\leq 20799$ & 11.05 & $-12.48,-5.90$ & -9.19 & $-12.48,-5.90$ & -7.89 & $-11.26,-4.51$ & -7.25 & $-10.74,-3.76$ \\
\hline Food-cost concern & $n-$ & - & - & - & -0.11 & $-0.18,-0.04$ & -0.11 & $-0.18,-0.04$ \\
\hline \multicolumn{3}{|l|}{$\begin{array}{l}\text { Deviance } \\
P \text {-value for } \\
\quad \text { deviance test }\end{array}$} & \multicolumn{2}{|r|}{8504.72} & \multicolumn{2}{|c|}{$\begin{array}{c}8494.64 \\
0.0015 \S\end{array}$} & \multicolumn{2}{|c|}{$\begin{array}{l}8488.01 \\
0.1567 \S\end{array}$} \\
\hline
\end{tabular}

$\mathrm{Cl}$ - confidence interval.

*Analyses adjusted for age and sex of person in household mostly responsible for food purchasing.

† Scale measuring food cost concern ranged from 0 to 100 .

$\ddagger$ Scale measuring grocery food purchasing ranged from 0 to 100 .

$\S P$-value for the difference between the deviance for Model 2 and Model 3.

I $P$-value for the difference between the deviance for Model 3 and Model 4 
$P=0.0015)$. Model 3 was further adjusted for the respondent's education level (Model 4) and this had little effect on the association between household income and food purchasing. Moreover, the inclusion of education did not significantly improve the overall model fit $\left(\chi^{2}=6.63\right.$, $P=0.157)$.

\section{Discussion}

In the present paper we extend and complement earlier studies that examined socio-economic differences in food and nutrient intake by showing a strong and often graded association between education and food purchasing behaviour, and household income and behaviour. Moreover, we clearly demonstrated that socio-economic differences in dietary knowledge represented part of the pathway through which education attainment exerts its influence on diet; and also that food purchasing differences by household income were related to diet in part via food-cost concern.

The findings of this study are highly relevant for developers of health promotion messages or dietary guidelines, as they show that respondents who attained no educational qualifications beyond school and those in lowincome households were less likely to purchase grocery foods that were high in fibre and low in fat, salt and sugar. One of the broader implications of these findings is that whilst national dietary promotion and interventions have seemingly been effective in terms of changing some dietary behaviours in ways that are likely to benefit long-term health $^{5}$, population-wide approaches do not necessarily alter underlying dietary inequalities. Thus national efforts to improve diet need to be complemented by targeted policies and promotions that are designed with, and especially for, socio-economically disadvantaged groups.

A further important contribution of this present work is that it extends the findings of previous studies that report an association between SEP and dietary knowledge ${ }^{24}$ by showing that educational differences in knowledge were significantly related to educational differences in food purchasing behaviour. Again, these findings will be salient for those involved in diet-related health promotion. In particular, despite earlier studies finding a weak or no association between knowledge and $\operatorname{diet}^{39,40}$, more recent work based on better conceptualised and measured indicators of knowledge shows that dietary intake and behaviour are influenced to a significant extent by a person's stock of dietary knowledge ${ }^{41}$. Anecdotally, this is entirely consistent with what we would expect to occur in everyday life: it seems wholly unrealistic to conceive that people purposefully choose healthy food (e.g. low-fat milk or high-fibre bread) in the absence of any understanding of the basis of their actions.

Similarly, we have extended the results of studies that find an association between income and $\operatorname{diet}^{4,15,42}$ by showing that concerns about food costs among low-income families influenced their propensity to purchase healthy food. The fact that food-cost concern represented a barrier to the purchase of healthy food among low-income households points to a possible discordance between people's subjective perceptions of the cost of healthy food and objectively measured reality. Clearly, perceptions (factually correct or incorrect) are a powerful influence on behaviour; however, an Australian study has shown that the costs of recommended and regular foods (e.g. low- and full-fat milk) are very similar and in many cases identical ${ }^{21}$. Other Australian studies have estimated that diets consistent with dietary guidelines cost the same and are often less expensive than more 'traditional' diets; thus it is argued that healthy diets in this country are affordable by most families, including those on relatively low incomes ${ }^{43,44}$. Taken together, the findings of these studies, and those documented in this present paper, suggest that future health promotion efforts could focus on instilling the message that healthy food very often costs no more than foods comprising a traditional diet.

\section{Study limitations}

In previous dietary studies, researchers have defined as problematic the practice of using a single socio-economic indicator to model the association between SEP and diet, thus failing to take account of possible residual confounding $^{22,23}$. In particular, it is argued that because measures of SEP correlate, the use of a single socio-economic indicator in dietary analyses will produce over-inflated parameter estimates for that indicator, leading to inaccurate population inferences. One suggested way of dealing with residual confounding is to include multiple measures of SEP in the model to absorb the shared variance between the indicators, therefore allowing a clearer assessment of the relationship between the socio-economic factor of interest and diet. We adopted this approach in our present study; however our results suggest that simultaneous adjustment for multiple socio-economic indicators can introduce its own inherent problems. One of the findings to have emerged from studies that adopt a life-course approach to investigate health inequalities is that education, occupation and income follow a temporal ordering and are often determinative ${ }^{45}$, with a person's level of education likely to influence their occupational status, which in turn influences their earning potential ${ }^{46,47}$. These findings should directly inform how we specify our analytical models, otherwise we run the risk of 'over-adjusting' our models. In terms of the present study, including education and income in the same model in an attempt to isolate and better delineate the effects of education on food purchasing behaviour seemingly constituted over-adjustment, as education's effect on diet was likely to partially operate through income. This process was supported by the marked attenuation of the relationship between education and purchasing behaviour after adjustment for income. 
Importantly, this same analytical model theorised differently did not apparently constitute over-adjustment, as including education and income in the same analysis to more accurately identify the relationship between income and food purchasing behaviour was arguably appropriate, as it was desirable in this particular model specification to remove any residual confounding due to education's association with income. This was supported by our results showing that the relationship between income and food purchasing behaviour was only marginally affected by adjustment for education. Dietary researchers thus need to specify their socio-economic models more circumspectly and preferably on the basis of our extant understandings of the temporal and determinative relationships among the different socio-economic indicators and how these relate to the dietary outcome under study.

The findings of this study are based on a research design that achieved a moderate response rate of $66.4 \%$; thus we need to consider the likely direction and magnitude of bias associated with the $33.6 \%$ non-response, and how these might affect this study's inferences to the wider population. Previous studies show that persons from socio-economically disadvantaged backgrounds are least likely to participate in survey research ${ }^{48}$. As a result, population-based samples typically under-represent the most disadvantaged, the likely consequence of which is a socio-economically truncated sample, resulting in an underestimation of the magnitude of socio-economic variability in the dietary factors being investigated ${ }^{49}$. The socio-economic differences in knowledge, food-cost concern and purchasing behaviour reported in this paper, therefore, are likely to be underestimates of the 'true' magnitude of socio-economic differences in the Brisbane population.

\section{Conclusions}

Socio-economic differences in food purchasing behaviour may contribute in part to the now well established associations showing socio-economic differences in food and nutrient intakes and, ultimately, to socio-economic differences in mortality and morbidity rates for diet-related diseases. Moreover, socio-economic differences in dietary knowledge and food-cost concern seem to play a significant role in these relationships, and hence could form the focus of future healthy eating messages and education campaigns.

This paper's approach to the modelling of socioeconomic indicators produced findings that challenged some established modelling practices and reaffirm the importance of appropriate (theoretically informed) model conceptualisation and specification. The work has also highlighted a number of as yet unresolved problems with how we appropriately examine the relationship between SEP and diet in ways that maximise the accuracy of our model estimates.

\section{Acknowledgements}

G.T. is supported by a National Health and Medical Research Council/National Heart Foundation Career Development Award (CR 01B 0502). A.M.K. is supported by a Victorian Health Promotion Foundation (VicHealth) Senior Research Fellowship.

\section{References}

1 Billson H, Pryer JA, Nichols R. Variation in fruit and vegetable consumption among adults in Britain: an analysis from the dietary and nutritional survey of British adults. European Journal of Clinical Nutrition 1999; 53: 946-52.

2 De Irala-Estevez J, Groth M, Johansson L, Oltersdorf U, Prattala R, Martinez-Gonzalez MA. A systematic review of socioeconomic differences in food habits in Europe: consumption of fruit and vegetables. European Journal of Clinical Nutrition 2000; 54: 706-14.

3 Giskes K, Turrell G, Patterson C, Newman B. Socioeconomic differences among Australian adults in consumption of fruit and vegetables and intakes of anti-oxidants and folate. Journal of Human Nutrition and Dietetics 2002; 15: 375-85.

4 Turrell G. Determinants of healthy food choice in a population-based sample. American Journal of Health Behavior 1998; 22: 342-57.

5 Turrell G. Compliance with the Australian dietary guidelines in the early 1990's: have population-based health promotion programs been effective? Nutrition and Health 1997; 11: $271-88$.

6 James WPT, Nelson M, Leather S. The contribution of nutrition to inequalities in health. British Medical Journal 1997; 314: 1545-9.

7 Davey Smith G, Brunner E. Socioeconomic differentials in health: the role of nutrition. Proceedings of the Nutrition Society 1997; 56: 75-90.

8 Kaplan GA, Keil JE. Socioeconomic factors and cardiovascular disease: a review. Circulation 1993; 88: 1973-98.

9 Cooper R, Cutler J, Desvigne-Nickens P, Fortmann SP, Friedman L, Havlik R, et al. Trends and disparities in coronary heart disease, stroke and other cardiovascular diseases in the United States: findings of the national conference on cardiovascular disease prevention. Circulation 2000; 102: 3137-47.

10 Rooks RN, Simonsick EM, Miles T, Newman A, Kritchevsky $\mathrm{SB}$, Schulz R, et al. The association of race and socioeconomic status with cardiovascular disease indicators among older adults in the health, aging and body composition study. Journals of Gerontology. Series B, Psychological Sciences and Social Sciences 2002; 57: S247-56.

11 Tang M, Chen Y, Krewski D. Gender-related differences in the association between socioeconomic status and selfreported diabetes. International Journal of Epidemiology 2003; 32: 381-5.

12 Everson SA, Maty SC, Lynch JW, Kaplan GA. Epidemiologic evidence for the relation between socioeconomic status and depression, obesity, and diabetes. Journal of Psychosomatic Research 2002; 53: 891-5.

13 Mullins CD, Cooke JL, Wang J, Shaya FT, Hsu DV, Brooks S. Disparities in prevalence rates for lung, colorectal, breast, and prostate cancers in Medicaid. Journal of the National Medical Association 2004; 96: 809-16.

14 Ward E, Jemal A, Cokkinides V, Singh GK, Cardinez C, Ghafoor A, et al. Cancer disparities by race/ethnicity and socioeconomic status. CA Cancer Journal for Clinicians 2004; 54: 78-93. 
15 Turrell G, Hewitt B, Patterson C, Oldenburg B, Gould T. Socioeconomic differences in food purchasing behaviour and suggested implications for diet-related health promotion. Journal of Human Nutrition and Dietetics 2002; 15: 355-64.

16 Shimakawa T, Sorlie P, Carpenter MA, Dennis B, Tell GS, Watson R, et al. Dietary intake patterns and sociodemographic factors in the Atherosclerosis Risk in Communities Study. Preventive Medicine 1994; 23: 769-80.

17 Smith A, Baghurst K. Public health implications of dietary differences between social status and occupational category groups. Journal of Epidemiology and Community Health 1992; 46: 409-16.

18 Crotty P, Rutishauser I, Cahill M. From food to nutrients and back. Proceedings of the Nutrition Society of Australia 1991; 16: 38 .

19 National Health and Medical Research Council. Dietary Guidelines for Australian Adults. Canberra: AusInfo, 2003.

20 Strategic Intergovernmental Nutrition Alliance. Eat Well Australia: An Agenda for Action for Public Health Nutrition. Canberra: National Public Health Partnership, 2001.

21 Turrell G. Structural, material, and economic influences on the food purchasing choices of socioeconomic groups. Australian and New Zealand Journal of Public Health 1996; 20: $611-7$.

22 Galobardes B, Morabia A, Bernstein M. Diet and socioeconomic position: does the use of different indicators matter? International Journal of Epidemiology 2001; 30: $334-40$.

23 Turrell G, Hewitt B, Patterson C, Oldenburg B. Measuring socio-economic position in dietary research: is choice of socio-economic indicator important? Public Health Nutrition 2003; 6: 191-200.

24 Parmenter K, Waller J, Wardle J. Demographic variation in nutrition knowledge in England. Health Education Research 2000; 15: 163-74.

25 Macario E, Emmons KM, Sorensen G, Hunt MK, Rudd RE. Factors influencing nutrition education for patients with low literacy skills. Journal of the American Dietetic Association 1998; 98: 559-64.

26 Busselman KM, Holcomb CA. Reading skill and comprehension of Dietary Guidelines by WIC participants. Journal of the American Dietetic Association 1994; 94: 622-5.

27 Robinson N, Caraher M, Lang T. Access to shops: the views of low-income shoppers. Health Education Journal 2000; 59: $121-36$.

28 Barratt J. The cost and availability of healthy food choices in southern Derbyshire. Journal of Human Nutrition and Dietetics 1997; 10: 63-9.

29 Sooman A, Macintyre S, Anderson A. Scotland's health - a more difficult challenge for some? The price and availability of healthy foods in socially contrasting localities in the West of Scotland. Health Bulletin 1993; 51: 276-84.

30 Turrell G, Patterson C, Oldenburg B, Gould T. The socioeconomic patterning of survey participation and nonresponse error in a multilevel study of food purchasing behaviour: area- and individual-level characteristics. Public Health Nutrition 2003; 6: 181-9.
31 Australian Bureau of Statistics. Socioeconomic Indexes for Areas, 1996. Catalogue No. 2039.0. Canberra: Australian Government Publishing Service, 1998.

32 Australian Bureau of Statistics. Income Distribution 19992000. Catalogue No. 6523.0. Canberra: Australian Government Publishing Service, 2001.

33 Trent LK. Nutrition knowledge of active-duty navy personnel. Journal of the American Dietetic Association 1992; 92: 724-8.

34 Hatcher L. A Step-by-Step Approach to Using the SAS System for Factor Analysis and Structural Equation Modelling. Cary, NC: SAS Institute Inc., 1994.

35 Commonwealth Department of Health and Family Services. Australian Guide to Healthy Eating. Canberra: Australian Government Publishing Service, 1998.

36 Simpson JM, Klar N, Donner A. Accounting for cluster randomization: a review of primary prevention trials, 1990 through 1993. American Journal of Public Health 1995; 85: $1378-83$.

37 Korn EL, Graubard BI. Analysis of large health surveys: accounting for the sampling design. Journal of the Royal Statistical Society 1995; 158: 263-95.

38 Rahbash J, Browne W, Goldstein H, Yang M, Plewis I, Healy M. A User's Guide to MLwiN. London: Centre for Multilevel Modelling, 2000.

39 Stafleu A, Van Staveren WA, De Graaf C, Burema J. Nutrition knowledge and attitudes towards high-fat foods and low-fat alternatives in three generations of women. European Journal of Clinical Nutrition 1996; 50: 33-41.

40 Shepherd R, Towler G. Nutrition knowledge, attitudes and fat intake: application of the theory of reasoned action. Journal of Human Nutrition and Dietetics 1992; 5: 387-97.

41 Wardle J, Parmenter K, Waller J. Nutrition knowledge and food intake. Appetite 2000; 34: 269-75.

42 Giskes K, Turrell G, Patterson C, Newman B. Socioeconomic differences in fruit and vegetable consumption among Australian adolescents and adults. Public Health Nutrition 2002; 5: 663-9.

43 Maggiore $\mathrm{P}$. Is a healthy diet affordable for families on a low income? Australian Journal of Nutrition and Dietetics 1991; 48: 38-9.

44 Lawson JS. Food consumption based on dietary guidelines can cost less than traditional diets. Australian Journal of Public Health 1993; 17: 397-8.

45 Kuh D, Ben-Shlomo Y, eds. A Life Course Approach to Chronic Disease Epidemiology, 2nd ed. Oxford: Oxford University Press, 2004.

46 Psacharoupoulos G. Returns to education: a further international update and implications. Journal of Human Resources 1985; 20: 583-604.

47 Azuma Y, Grossman HI. Educational inequality. Labour 2003; 17: 317-35.

48 Turrell G. Income non-reporting: implications for health inequalities research. Journal of Epidemiology and Community Health 2000; 54: 166-72.

49 Turrell G, Najman JM. Collecting food-related data from low socioeconomic groups: how adequate are our current research designs? Australian Journal of Public Health 1995; 19: $410-6$. 


\section{University Library}

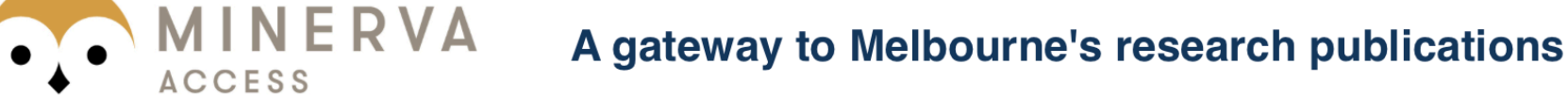

Minerva Access is the Institutional Repository of The University of Melbourne

Author/s:

TURRELL, GAVIN;Kavanagh, Anne M.

Title:

Socio-economic pathways to diet: modelling the association between socio-economic position and food purchasing behaviour

Date:

2006

Citation:

Turrell, G. \& Kavanagh, A. M. (2006). Socio-economic pathways to diet: modelling the association between socio-economic position and food purchasing behaviour. Public Health Nutrition, 9(3), 375-383.

Publication Status:

Published

Persistent Link:

http://hdl.handle.net/11343/34455 